\title{
Towards a Phenomenological Analysis of Fictional Emotions
}

\author{
Marco Cavallaro \\ University of Cologne \\ marco.cavallaro@uni-koeln.de
}

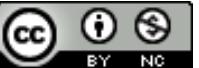

\begin{abstract}
What are fictional emotions and what has phenomenology to say about them? This paper argues that the experience of fictional emotions entails a splitting of the subject between a real and a phantasy ego. The real ego is the ego that imagines something; the phantasy ego is the ego that is necessarily co-posited by any experience of imagining something. Fictional emotions are phantasy emotions of the phantasy ego. The intentional structure of fictional emotions, the nature of their fictional object, as well as the process of constituting the phantasy ego in representificational acts of consciousness are further elaborated to provide the groundwork for a phenomenological analysis of fictional emotions.
\end{abstract}

Keywords: Imagination, Emotion, Phenomenology, Edmund Husserl, Ego-Splitting

In everyday life as well as in philosophical discourse, it is common to distinguish fictional emotions from ordinary emotions. Being afraid for the spider on the wall in front of me is different from being afraid for the image of a spider in a picture or for simply imaging a spider. Whereas the distinction between fictional and ordinary emotions is a commonplace, it is less easy to identify the proper difference underlying it. In fact, from a physiological point of view there is little till nothing difference between real and fictional emotions. The physiological and visceral changes in an individual scared by a horror movie are identical to those of a person genuinely afraid. The effects on the body, namely an increased heart rate, rapid breathing, and even changed brain activity, are in both cases the same. Thus, the difference between real and

ISSN: 0874-9493 (print) / ISSN-e: 2183-0142 (online)

DOI: 10.2478 /phainomenon-2019-0004

(C) 2019 Cavallaro. This is an open access article licensed under the Creative Commons Attribution-NonCommercial-NoDerivs License (http://creativecommons.org/licenses/by-nc$\mathrm{nd} / 3.0 /)$. 
fictional fear is not detachable through the methods of objective science. The problem of distinguishing real from fictional emotions is rather of philosophical kind.

This paper argues that what most properly distinguishes fictional emotions from ordinary emotions is the fact that the former are phantasy emotions of the phantasy ego. To do so it discusses the nature of the fictional object, the intentional structure of fictional emotions, as well as the process of constituting the phantasy ego in representificational acts of consciousness. Taken together, these analyses aim to provide the groundwork for a phenomenological analysis of fictional emotions.

\section{The object(s) of fictional emotions}

There are at least two ways of grounding the distinction between fictional and ordinary emotions. One can refer to either the difference of their respective objects or that of their respective phenomenological character. In the first case, the distinction is ontological since it grounds on the ontological character of the emotions' proper object. In the second case, the distinction is phenomenological insofar as it grounds on the inner structure of the emotional acts that are funded on the imagination of fictional objects. In this section we tackle the first way of grounding the distinction between fictional and ordinary emotions by referring to the different nature of their respective objects.

We start by acknowledging this simple fact: The object of ordinary emotions is existent, whereas that of fictional emotions is not. For instance, I take the spider on the wall in front of me as being existent. Fearing the spider implies both an existence-belief concerning the spider and a belief concerning its dangerousness. I believe in the existence of the spider; I believe that spiders are dangerous living beings; both beliefs taken together motivate my being afraid. Would I not harbor any belief about the existence of the spider on the wall in front of me, I were not afraid. Therefore, existence-beliefs seem to be a necessary component of ordinary emotions like fear. 
On the other hand, if I would take the spider as non-existent and nevertheless fear it, the argument goes, I would be feeling a fictional emotion. ${ }^{1}$ Fictional emotions are not a case of ordinary emotions, insofar as one grants that ordinary emotions necessarily entail existence-beliefs, while fictional emotions lack precisely this kind of beliefs concerning their own object. But still granting this general assumption, one could further ask in which sense fictions entail a reference to non-existence-beliefs. Thus, determining the difference between ordinary and fictional emotions relates to the problem of establishing whether or not (and, possibly, how) fictional objects are to be taken as existent objects.

Fictional emotions are emotions elicited by imaginative representations. Imagination is commonly understood as the way of representing, intending, or referring to a non-existing object, i.e. a fiction (cf. Marbach, 2013). ${ }^{2}$ There are different ways of imagining something. Following Edmund Husserl, we distinguish two forms of imaging: seeing in or picture consciousness and simple imaging or pure phantasy. Seeing a centaur in an image is a different experience from simply imaging it. First, I need to perceive a physical image, e.g. a picture, that depicts the centaur. The activity of seeing in grounds on the consciousness of conflict between the perception of the physical image and the imagination of the image object, i.e. the centaur as appears in the picture. Second, my imagination of the centaur (image subject) is limited by the representation of the centaur in the picture (image object). I cannot freely imagine the centaur, but while seeing the centaur in the picture I imagine the centaur in the manner in which it is represented in the picture. Seeing a centaur in a picture, I am not as free as when I imagine a centaur in an act of pure phantasy. Purely imaging

\footnotetext{
${ }^{1}$ The conditional is here necessary, since it has not been argued so far that fictional emotions are possible experiences. As a matter of fact, a significant part of the debate on fictional emotions centers around the question about the possibility of experiencing something like emotional responses to fictions.

${ }^{2}$ Not all philosophers agree with this characterization of imaging. For instance, Edward S. Casey lists four alternatives ways in which the imagined object may be posited: besides nonexistence, the other three are neutrality, absence, and existence elsewhere (Casey, 1971: 478, ft. 9). Fictionality is understood as akin to non-existence. Following Wolfgang Künne (2016), we employ 'fictive' as ontological predicate and 'fictional' for semantic or semiotic use. Accordingly, fictional emotions are not illusional emotions, i.e. merely fictive emotions.
} 
a centaur means that the act of imagination does not rely on the perception of a physical image. Here is no picture of a centaur in which I 'see' the centaur. Rather, I close my eyes and mentally engage myself in the imagination of a centaur.

When in this paper we speak of fictional emotions without further qualification, we refer to both seeing in and simple imaging as experiential basis of emotional responses. In the following, we take the experience of looking at pictures or "image consciousness" as the chief example for fictional emotions, but the same would apply to proper imaging or "pure phantasy" as well, i.e. the experience of representing a fictional object without the aid of images (paintings, sculptures, films, or theatrical productions). ${ }^{3}$ We shall see that from a phenomenological perspective, it is controversial to argue for the non-existence of both the image of the spider on a picture and the depicted spider — in Husserl's terminology image object and image subject, respectively (see Husserl, 2005: $584 \mathrm{f}$.). Let us focus now on the depicted spider or image subject first, while turning afterwards to the pictorial image of the spider or image objet.

In the example above, we said that I see a spider in the picture. The picture itself or image thing is different from the spider that it depicts. It hangs on the wall in front of me and is as real as the spider I see moving aside it. The physical object 'picture' hanging on the wall exists like myself, the perceiver, and the real spider exist. On the other hand, the depicted spider cannot be said to exist in the same manner as the picture, myself, and the real spider do exist. I know that spiders in general exist; so I suppose that the picture depicts an existing spider. Although the depicted spider does not exist here and now, I suppose that it now exists somewhere else or existed in the past here or somewhere else, when the picture was taken. ${ }^{4}$ The mode of existence of the depicted spider is

\footnotetext{
${ }^{3}$ The expressions "image consciousness" and "pure phantasy" stem from Husserl. For a good overview of Husserl's general theory of imaging and phantasy see Brough (2005) and Marbach (2013). Rozzoni (2017) provides an excellent introduction into Husserl's theory of image consciousness and the problems of a phenomenological aesthetics in Husserlian spirit.

${ }^{4}$ The experience of any photographic picture implies the existential positing of its image subject, i. e. the photographic subject, in the past. This distinguishes photographic looking from the experience of looking at paintings. Furthermore, there
} 
being-now-somewhere-else or being-in-the-past; that of the real spider is beingnow-here. For this reason, it is not properly true to say that the spider for which I am afraid does not exist. The spider which I see in the picture existed or exists now somewhere else and this existing object is also that for which I am afraid. ${ }^{5}$

Therefore, the thesis according to which existence-beliefs are a necessary component of emotions needs some refinement. Existence might mean beingnow-here, being-now-somewhere-else, or being-in-the-past. If one grants that any emotion has an existence-belief at its core, for each case it is necessary to specify what kind of existence-belief lays at the emotion's core. Furthermore, one can possibly categorize emotions according to the character of their grounding existence-beliefs. Certain emotions have at their core beliefs about the being-now-here of their objects. As noted above, fear seems to belong to this category of emotions. Other emotions have at their core beliefs about the being-in-the-past of their objects. Nostalgia seems to be an emotion of this kind, since its object is a moment past whose loss the subject mourns. ${ }^{6}$ Strictly speaking, nostalgia should be kept distinct from homesickness. If you are homesick, you feel unhappy because you are away from home and are missing your family, friends, and home. All these are objects existing now somewhere else. Thus, at the core of homesickness there is the belief about the being-nowsomewhere-else of an object. In sum, these categories of emotion have at their core a belief about the existence of their respective objects and hereby qualify

is a strict connection between photographic experience and nostalgic reverie. Unfortunately, I cannot further argue for these points in the present paper due to space constraints.

${ }^{5}$ One might object to this claim that we do in fact have pictures of imaginary, fictional objects too. A confusion might arise from the fact that we took the photograph of a spider as chief example. As we noticed in the previous footnote, photographs are a very peculiar kind of pictures, whose object must be an existent one (or it has to have been in the past). But paintings, sculptures, or movies might depict utterly fictive objects like centaurs, hippogriffs, fairies and so on. Therefore, it is correct to notice that, in this view, if the picture is not a photograph, the image subject can elicit emotional responses that qualify as fictional.

${ }^{6}$ Some describe the object of nostalgia in terms of a fictional object, the nostalgic past being widely the result of an act of productive imagination (see Bernet, 2007). On this account, nostalgia would belong to the category of fictional emotions. 
as ordinary emotions. What distinguishes them is precisely the existence-mode of their object. On the contrary, fictional emotions seem to belong to a totally different category of emotions.

The way of grounding the distinction between fictional and ordinary emotions on the different character of their respective existence-beliefs seems to be a promising one. However, it also has its pitfalls. As we noticed, there are emotions whose core belief regards the being-in-the-past or being-nowsomewhere-else of their objects. These emotions do not qualify as fictional, though. For there is a certain sense in which an emotion like homesickness, for instance, distinguishes itself from the fictional fear elicited by the experience of seeing a spider in a picture. To discriminate between the two is not enough to refer to the existence-mode of the depicted object, since our discussion so far showed that depicted objects are not necessarily fictional objects. Fictional emotions ground on beliefs about fictional objects. Therefore, if we are still prone to qualify emotions elicited by pictures (any kind of) as fictional, the distinction between ordinary and fictional emotions has to be found in the case of the experience of looking at pictures on the part of the image object.

A better way of interpreting the fictional fear of seeing a spider in the picture suggests identifying the object of the emotion not in the depicted spider or image subject, but in the image of the spider in the picture or image object. What most properly distinguishes fictional emotions from ordinary emotions is the fact that the latter are about existing objects while the former about nonexisting, fictional objects. We normally take the image of the spider in the picture as non-existing. ${ }^{7}$ Thus, the proper object of a fictional emotion related to the experience of looking at pictures is the image object.

It is important to stress here once more the difference between picture and image object. As we previously said, the picture is a real thing hanging on the wall in front of me. It is part of the spatiotemporal world in which I myself and all other real objects exist. On the opposite, the image of the spider, to which I have access through the real picture hanging on the wall, is not itself real. One can set the picture on fire, the image will not burn. One can turn the picture upside down, the image itself will not be turned. The picture presents tactual properties like coarseness, graininess, coldness and so on, which the image does

\footnotetext{
${ }^{7}$ This holds true for any kind of picture, i.e. also for photographic ones.
} 
not have. These properties themselves might in some cases elicit emotional responses on the perceiver of the picture; however, they do not qualify as fictional since their objects are real, existing qualities of a real, existing physical thing.

While seeing a spider in a picture, the animal (image object) is not posited as existent, even though the physical image in which the spider is depicted is real and the depicted spider (image subject) might have existed in the past or exist now somewhere else. Looking at pictures, it might be the photograph of a spider, the still lifes of Giorgio Morandi, or the moving pictures of a movie, we depart from our natural attitude of positing the seen object as real. As Husserl remarks about a painting by Titian, "I do not take what I see to be 'real'. It does not exist" (Husserl, 2005: 178). This feature distinguishes imaging ${ }^{8}$ in particular from perception. To perception belongs characteristically a belief in the existence of the perceptual object (Husserl, 2005: 270). If I perceive the spider, at the same time I posit its existence, which means, I believe that it exists here and now. On the contrary, imaging the spider, either by seeing it in a picture or simply imaging it hovering before me on the wall, I do not posit it as existent.

Notice that we said 'I do not posit it as existent' and not 'I posit it as nonexisting'. Indeed, the two sentences express two quite different phenomena. To posit something as non-existing involves the performance of a position-taking, i.e. engaging in a belief about the non-existence of a certain object. While believing in the non-existence of something is the contrary of believing in its existence, imaging an object is not the contrary of believing in its existence. For when imaging, we do not posit something as non-existing like when we say that a golden mountain does not exist. Imaging a golden mountain is different from positing the golden mountain as non-existing, for in the first case I am not interested in the existence or non-existence of the object. The object, the golden mountain, simply appears as if it exists. This has nothing to do with my belief about the non-existence of the golden mountain. Only if I engage in a higherorder act of reflecting upon my imaging of a golden mountain and compare the

\footnotetext{
${ }^{8}$ I refer here to imaging as a general concept which can be further specified in terms of image consciousness and imaging proper or pure phantasy.
} 
fictional object of my imagination with the objects of the real world, without finding any matching, I am prone to conclude that what I imagine does not exist. Thus, besides the fact that positing the non-existence of the fictional object is an activity that takes place beside and on top of the very act of imaging, the positing of non-existence is different in kind from the positing proper to imaging.

Husserl employs three qualifying phrases to capture the unique character of imaging positing: "as it were (gleichsam)", "as if (als ob)", and "quasi-" (see Brough, 2005: xxxvii). All these expressions refer to imaging's capacity of quasi-positing the existence of fictional objects. The existence of a fictional object, i.e. an object of imaging, like the golden mountain or the image of the spider I see in the picture, qualifies as quasi-existence or existence-as-if. ${ }^{9}$ For this reason, it is incorrect to say that fictional objects do not exist, so long as one interprets this as akin to the claim that we pose fictional objects as nonexisting objects. Fictional objects are neither existing nor non-existing objects. Instead, they possess a kind of existence (and non-existence) ${ }^{10}$ which differs from that of ordinary objects.

It is not my intent here to elaborate further on the ontological character of fictional objects, since this would go beyond the scope of this paper. However, a brief remark is still necessary for the present discussion. One might be tempted to interpret the as-if-mode of fictional objects in terms of possibility. ${ }^{11}$ In several places, Husserl himself equated the objects of imaging with possible objects, conflating imaging with supposing (cf. for instance Husserl, 2005: 671,

${ }^{9}$ That the positing as-if of the fictional object implies at the same time a quasiperceiving of the fictional object will become clear below when discussing the intentional character of fictional emotions.

${ }^{10}$ While engaging in the experience of a phantasy world, I can 'find out' that in this world there are no hippogriffs. This means, in the act of imaging I posit hippogriffs as quasi-non-existing.

${ }^{11}$ Edward Casey is a prominent example of this tendency. Casey thinks that "there is a special thetic modification involved in all prototypical imagining. This concerns the positing of the imagined object as 'merely possible' [...]. The imagined object thus possesses an existential status of its own: that of pure possibility, which cannot be explicated in terms of reality or unreality or a mixture of the two together" (Casey, 1971: 478). 
681). He thought that a fictional object, as a quasi-object, could be nothing other than a possibility. In this view, possibility, and not non-existence, represents the opposite of existence, intended as actuality (Wirklichkeit). An object can either actually exist or possibly exist, tertium non datur. Since a fictional object does not actually exist, its mode of existence must be that of possibility. ${ }^{12}$ Nonetheless, Husserl eventually came to revise his understanding of the relationship between possibility and phantasy. In 1923 he writes that we must distinguish the fictional object from any possibility that might be drawn from it (Husserl, 2005: 687), and adds that "one could run into confusion if one took

12 Julia Jansen especially underlines phantasy's capacity of constituting possibilities in her account of Husserl's transcendental phenomenology of imagination. Phantasy can be said to posit possibilities because, she argues, "[w] hat can be seen as an as ifappearance of an actual object is in fact also an actual appearance of a possible object" (Jansen, 2005a: 126; see also Jansen, 2005b: 234 f.). In claiming this, Jansen purportedly draws only on Husserl's early account of imagination. Exegetical problems aside, one could object against this view, first, that we do also have phantasies of nonactual objects as when we imagine remembering a past event that never took place. An imagined memory is the non-actual as if-appearance of a non-actual object. Second, one needs to further specify the character of the possibility here at stake. Not every as if-appearance of an actual object is an appearance of a possible object, if possibility is understood as real possibility. A golden mountain is not a real possibility, thus imaging a golden mountain does not amount to an actual appearance of a possible object. Identifying phantasy possibility with pure possibility, as for instance Casey does (see Casey, 1971: 476), is even more problematic. A pure possibility can be identical across multiple acts and perceivers. If I identify through eidetic variation the possibility of perceiving colors without sounds, this pure possibility holds true for me at different points in time and for every possible subject capable of perceiving. In opposition to pure possibilities, fictional objects are not identical across multiple acts and perceivers. On the one hand, I cannot be confident that what I am now imaging is precisely the same object or possibility that I imagined earlier, rather than "merely one that is like it" (Husserl, 2005: 662). Similarly, several subjects cannot claim to be aware of the same imagined object, since, as Husserl argues, "it makes no sense to say that an 'individual' centaur that one subject invents and that another subject invents is the same" (Husserl, 2005: 684), given that each subject creates his or her own phantasy world (Husserl, 2005: 686). At the root of these differences is the subjectivity of phantasy: "what is phantasied is absolutely subjective and not something in itself; possibilities, however, do exist in themselves. Suppositions are not phantasies" (Husserl, 2005: 687). 
phantasies, without further ado, to be possibilities" (Husserl, 2005: 684, note 2). John B. Brough comments on this shift in Husserl's understanding of phantasy arguing that "Husserl came to distinguish between phantasy and possibility at least in part because the objects of phantasy are not taken to be existent or 'geared' toward a decision about their existence; indeed, the whole issue of possible existence does not arise in pure phantasy" (Brough, 2005: xliii). As Brough's commentary correctly emphasizes, and as already pointed out before, imaging an object we are not interested in its existence at all. Since possibility is a modality of existence as opposed to actual existence, this implies that imaging an object we are not interested in its possible existence neither. While imaging we enter a new kind of attitude different from the natural one we engage in in everyday, practical life. ${ }^{13}$ The natural attitude is an attitude of existence (or non-existence) positing. The phantasy attitude excludes from its horizon of interests any question related to the actual or possible existence (or non-existence) of its objects.

We return now back to the topic of this paper by recapitulating the steps made so far. We said at the beginning that fictional emotions are emotional responses to fictional objects. In order to distinguish fictional from ordinary emotions, we underwent a discussion on the nature of fictional objects. Our point of departure has been the experience of seeing objects in pictures. We noticed that the image subject or depicted object cannot be said to be the proper object of fictional emotions, because it is an object that existed in the past or is existing now somewhere else. In the case of the experience of looking at pictures, the object of the fictional emotion is thus the image object, which is at first taken as a non-existent object. We then differentiate non-existent objects which are explicitly posited as non-existent from fictional objects whose existence or non-existence is not taken into account by the phantasy attitude. Fictional objects are in a sense non-existent objects too, although the positing of their non-existence needs a further higher-order act of reflection which

\footnotetext{
13 "The change of attitude, then, is precisely the shift from actual experience, or, as the case may be, from the negation of actual experience, into phantasy, into the peculiar consciousness of the as-if, which, as one can no doubt say, is only made easy by the inhibiting that presents itself here. We submit to what appears as if it were reality" (Husserl, 2005: 614 f.). See also Ferencz-Flatz (2009: 249 ff).
} 
establishes their non-existence. The objects of fictional emotions are taken to be neither actually nor possibly existent objects. With this observation we conclude our path towards the ontological way of grounding the distinction between fictional and ordinary emotions.

\section{The intentional structure of fictional emotions}

The second way of grounding the distinction between fictional and ordinary emotions is to refer to their different phenomenological character. What might distinguish one kind of emotions from the other is in this case the difference, if any, between their mode of experience. It is keen at this point to distinguish between the phenomenological and the phenomenal character of experiences. The expression 'phenomenal character' indicates the way an experience is internally lived through by the experiencing subject. In the introduction, we noticed how the distinction between real and fictional emotions cannot be traced back to specific physiological and visceral differences in the subject's body. From a third-person perspective, thus, there is no detachable difference in the way one experiences, for instance, fictional or real fear. Things might be different when one turns the attention to the first-person phenomenal character of fictional emotions and compares it with that of ordinary emotions. It is not our intent to develop this point here, yet. What interests us is rather the phenomenological character of those experiences commonly labeled fictional emotions. The phenomenological character has less to do with the way experiences are internally lived through by subjects and more with the internal structure of the acts underlying them. What we are looking for here is what Husserl calls a phenomenological "intentional analysis" (Intentionalanalyse) of the structure of fictional emotions. In order to understand the phenomenological character of fictional emotions, we need first to specify the phenomenological character of emotions in general. Again, our analysis will closely follow Husserl's reflections on this topic.

The most fundamental proposition of Husserl's phenomenology of consciousness is the claim that consciousness is intentional experience (cf. 
Husserl, 2001: Fifth Logical Investigation, Ch. 2). ${ }^{14}$ This proposition, however, does not indicate that every consciousness constitutes an object. ${ }^{15}$ To explain this, Liangkang Ni has appropriately distinguished between a broad sense and a narrow sense of the concept 'intention' and 'intentional' in Husserl (cf. Ni, 2007: 70). Intentional in the narrow sense means object-constituting, whereby intentional in the broad sense means object-orientating. For Husserl not every experience is intentional in the narrow sense, while every experience is intentional in the broad sense. Presentations and judgments are intentional in the narrow sense insofar as they are object-constituting. Presentations objectify things, for instance this book on my desk. Judgments objectify states of affair, for instance the one expressed by the sentence 'the book is on the table'. Husserl call intentional acts in the narrow sense like presentations and judgments "objectifying acts" and distinguish them from "non-objectifying acts" (cf. Melle, 1990). Non-objectifying acts are acts that do not possess the mark of being object-constituting but nevertheless aim at, are orientated towards an object. Hence, they are intentional in the broad sense.

For Husserl emotions and feelings belong to the class of non-objectifying acts. This means that, on the one hand, they are directed toward an object or state of affair ${ }^{16}$ but, on the other hand, they do not constitute the objects and

${ }^{14}$ As it is well known, Husserl took this proposition from his master Franz Brentano. Brentano writes in his Psychology from Empirical Standpoint: "every mental phenomenon is characterized by what the mediaeval schoolmen called the intentional (or mental) inexistent of an object, and by what we, not without ambiguity, call the relation to a content, the direction to an object (by which a reality is not to be understood) or an immanent objectivity. Each mental phenomenon contains something as object in itself, though not all in the same manner" (Brentano, Psychologie vom empirischen Standpunkt, I: 115, as quoted by Husserl in Husserl [2001: 380]).

${ }^{15}$ I use here the term 'constitution' and its relatives 'constitutive', 'constitutional' etc. in a technical sense. For a classical introduction to Husserl's concept of constitution, see Sokolowski, 1970.

16 "'[H]uman experiences commonly classed as 'feeling' have an undeniable, real relation to something objective" (Husserl, 2001: 402). Similarly, "pleasure without anything pleasant is unthinkable. And it is unthinkable, not because we are here dealing with correlative expressions, as when we say, e.g., that a cause without an effect, or a father without a child, is unthinkable: but because the specific essence of pleasure demands a relation to something pleasing". And again, there is "no desire whose 
states of affair that they are directed to. Non-objectifying acts must be based on acts that constitute objects, i.e. objectifying acts, in order to manifest the property of being oriented towards objects. Thus, saying that all acts are intentional means that those acts which are not themselves object-constituting must merge with (at least) one objectifying act. Non-objectifying acts only emerge in compound with objectifying acts.

Fictional emotions do not make an exception to this rule. They are intentional in the broad sense insofar as they are directed towards an object, i.e. the fictional object, but they are not intentional in the narrow sense insofar as they do not constitute the object they intend. In this manner, they rely on a different act to manifest the property of being oriented towards fictional objects. The objectifying act fictional emotions are funded on is the act of imaging or what Husserl calls phantasy representifications (Phantasievergegenwärtigungen). In the course of his life, Husserl devoted a substantial number of lectures notes and manuscripts on the phenomenology of representifications. Representifications, as opposed to presentifications (Gegenwärtigungen) like perception, are those experiences whose distinctive character is to present an object that is absent from the actual field of perception. "We live in a present; we have a perceptual field of regard. In addition, however, we have appearances that present something not present lying entirely outside this field of regard" (Husserl, 2005: 63, translation modified). Intentional acts which possess this distinctive "[c]onsciousness of non-presence (Nichtgegenwärtigkeits-Bewusstsein)" (ibid.), which is typical of representifications, can be of different sorts. These include memories, expectations, making co-present (Gegenwartserinnerung), ${ }^{17}$ empathy, and phantasy or imagination. They are all intuitive experiences in the sense that they present their object in its full concretion without signitive intentions. Representifications differs from presentifications because the latter not only give the object as present and existing, but gives it "in person (leibhaftig)" (Husserl,

specific character can do without something desired, no agreement or approval without something agreed on or approved etc. etc." (Husserl, 2001: 404).

${ }^{17}$ Making co-present is a representificational consciousness of something that now exists but is not present to me (Husserl, 2005: 367), for instance, when I think of a familiar place, my hometown, as presently existing, even though at the moment I am nowhere near it and it does not enter into my perceptual field. 
2005: 601), as actually there confronting the perceiver. As Brough explains, "[p]resence in person involves both temporal presence - the object is perceived as now existing - and presence in the sense that the object is there, standing over against the perceiver and not re-presented as something presently existing but absent from the perceptual field of regard" (Brough, 2005: xxxiv). ${ }^{18}$ Thus, representificational acts are those acts that do not present their object in person, but only in absence, i.e. as it were there. ${ }^{19}$

Given the multiplicity of representificational acts and the fact that fictional emotions grounds on phantasy representifications, it becomes necessary to clarify the distinctive marks of representifications associated with phantasy with respect to other forms of representifications (i.e. memories, expectations, making co-present, and empathy). One might think that the mark of phantasy representifications lies in their being intentionally directed towards nonexistent objects. Memories are about past existent objects, expectations about future existent objects, making co-present about objects existing now somewhere else, and empathy gives us indirect access to the presence of the other and her intentional states. Therefore, it seems plausible to identify the mark of phantasy representifications in their capacity of rendering quasipresent non-existing objects. As we have previously seen, however, neither imaging is just about non-existent objects - I can in fact imaginatively representificate a really existing object or person being now in the room, although I know that it or she is not here; nor does the non-existence of phantasy objects imply that these are posited as non-existent in the very act of imaging.

\footnotetext{
${ }^{18}$ Brough employs in this text the now old rendering of the German Vergegenwärtigung with "re-presentation".

${ }^{19}$ Husserl writes: "We characterize perception as an act in which something objective appears to us in its own person, as it were, as present itself [selbst gegenwärtig]. In phantasy, to be sure, the object itself appears (insofar as it is precisely the object that appears there), but it does not appear as present. It is only re-presented [vergegenwärtigt]; it is as though it were there, but only as though. It appears to us in image. The Latins say imaginatio" (Husserl, 2005: 18). Cf. also ibid.: 107. On a related note, the quasi-presence of the phantasy object must not be confused with its quasiexistence. In the first case, we are talking of a phenomenological character of the object as experienced, in the second case we characterize the existence-mode of the object, thus we are referring here to the object as such and not to the object as experienced.
} 
Instead, imaginative representifications are possible only on the basis of a phantasy attitude that excludes any interest, that is, any position-taking, regarding actual or possible existence or non-existence of its respective objects. This peculiar attitude is thus what most precisely characterizes phantasy representifications with respect to other representifications.

\section{The Paradox of Fiction and the problems of a phenomenology of fictional emotions}

In the previous sections, we have been able to determine the ontological and intentional conditions for the experience of fictional emotions. This helped us to distinguish fictional emotions from ordinary emotions. Fictional emotions are emotional responses to imaginative experiences or phantasy representifications, whereby ordinary emotions are emotional responses to perceptions or presentifications. The former are about fictional objects, the latter about real objects. These distinctions, albeit informative about the inner structure of fictional emotions, still do not solve the problem connected to their very existence. Why do we experience something like emotional responses to fictions? How it can be possible to be afraid, say, of the spider in the picture, the murder scene in a horror movie, or the phantasy of one's own death?

Most contemporary philosophers agree that fictional emotions present us with a puzzle. The puzzle of fictional emotions has famously taken the form of a paradox, called the "paradox of fiction". ${ }^{20}$ The following argument shows that

\footnotetext{
${ }^{20}$ The first formulation of the paradox of fiction stems from Radford (1975). For a recent assessment of the debate on the paradox of fiction in analytic philosophy cf. Vendrell Ferran (2014). Recently, researchers working witihin the phenomenological tradition have been more and more interested in the topic. We mention here only two significant examples: Summa (2019) deals with the problem of determining the genuine and rational character of fictional emotions, which is the principal problem expressed by the paradox of fiction, while drawing on resources in the phenomenologies of Husserl and Jean-Paul Sartre; Vendrell Ferran (2010) shows how nowadays debate on the paradox of fiction have affinities with a debate between psychologists from the Brentano school at the beginning of Twentieth century, thereby uncovering the presuppositions of the phenomenological account of fictional emotions in Husserl and subsequent phenomenologists. Both approaches take up the issue expressed by the contemporary paradox of fiction and try to solve it from the point of view of
} 
admitting the existence of fictional emotions leads to a paradox: (a) In order for us to be emotionally moved by objects (people, situations etc.), we must have a belief in the existence of those objects. (b) When we engage with fictional objects, we are lacking an existence-belief concerning those objects. (c) We have an experience of being moved by fictional objects, i.e. non-existing objects. Taking together, these three premises form a paradox. The paradox depends on the plausibility of the three premises. It seems plausible that emotions are elicited by something existent. It seems plausible that we do experience fictional emotions and that those emotions are elicited by fictions. It seems plausible that fictions are non-existent objects. Claim (a) states all emotions are elicited by existent objects. Claim (c) states that there are some kinds of emotions which are elicited by non-existent objects (fictions). Claim (c) contradicts claim (a). Since we have reasons to believe that both claims are true, we face here a paradox.

For analytical philosophers, the challenge lies on the part of the logical analysis of the concept of emotion. Indeed, as Jerrold Levinson correctly emphasizes, "what underlies the paradoxicality of emotional responses to fiction [is] a matter of the conceptual impossibility of a response being an emotion if it does not include, or is not premise on, certain beliefs" (Levinson, 2006: 46, highlights are mine).The paradoxicality in stating the existence of fictional emotions grounds on two possible objections: fictional emotions are irrational and fictional emotions are non-genuine emotions. As Richard Moran in his own rendition of the paradox of fiction notices with reference to the irrationality of fictional fear, "to be afraid you must think you're in some kind of danger, and yet you know that the apparent object of your apparent fear is not real, so you know you are not in danger, and yet you seem to be stricken with fear" (Moran, 1994: 77). The problem concerning the genuineness of fictional emotions has been raised in particular by Kendall L. Walton in his classical work Mimesis as Make-Believe. On the Foundations of the Representational Arts (1990). Walton's solution to the paradox of fiction

phenomenology (in the broad sense). On the opposite, the intent of this paper is not to find a solution to the paradox, but to offer a phenomenological analysis of fictional emotions. This is also the reason why we introduce the paradox of fiction only at this late stage of our discussion. 
consists in modifying the third claim, which is, as we have seen, an experiential claim about the fact that we $d o$ experience emotions as response to fictions. Walton argues that emotional responses to fictions cannot be instances of ordinary, genuine emotions, but are instead instances of imaginary, or makebelieve, emotions. The paradox is in this way solved by rejecting as an experiential illusion the fact that we have such feelings as fictional emotions in the first place. Walton does not deny that we do feel some kind of emotions as emotional response to fictions. But he refuses to consider those emotions as emotions in the strict sense of the term, since an emotion would entail per definition the belief concerning the existence of its proper object. Fiction is a non-existing object, meaning that the experience of imaging a fiction does not contain any belief about the real existence of its object. Hence, when we talk about emotions as response to fictions, we use the concept of emotion in a different sense than the usual one. Fictional emotions, i.e. the ones we experience in response to fictions, are in this account fictive, imaginary emotions, which resemble but structurally differ from full-fledged emotions. ${ }^{21}$

It goes without saying that from a phenomenological standpoint the problem posed by the existence of fictional emotions is of a different kind. The paradox of fiction arises from a conceptual definition of emotions which is taken as natural or commonplace. According to this definition, emotions ground on existence-beliefs. Hence, the problem is to make sense of particular emotions, i.e. fictional emotions, that do not ground on an existence-belief about their objects. This approach is from a phenomenological perspective insofar misleading as it begins with a presupposition concerning the nature of emotions, instead of referring to experience itself in order to determine what emotions are. If we ask our natural experience, we are lent to claim that there are such things as fictional emotions, as when we look at spider in pictures, watch movies, or read novels. The problem is then not so much to justify either

${ }^{21}$ In fact, any possible solution to the paradoxicality of fictional emotions would resemble either the negation of the existence of such experiences as fictional emotions or the proposal of a new-fashioned conceptual definition of emotions which abandons the presupposition for which an emotion includes certain beliefs (for instance, the existence-belief concerning the object of emotion). 
existence, rationality, or genuineness of such emotions, as rather to distinguish them from ordinary emotions. ${ }^{22}$

A phenomenological viewpoint is confronted with a puzzling aspect of fictional emotions, which, although partly implied by the paradox of fiction, is not a puzzle concerning the concept of fictional emotions but rather their experiential character. The phenomenological question asks: what is the subject that is emotionally moved by fictional objects, people, and events? The next and last section attempts to provide an answer to this question.

\section{The subject of fictional emotions}

The guiding idea of this section is that the phenomenon of ego-splitting in phantasy experiences as envisaged by Husserl can help us to answer the question concerning the subject of fictional emotions. ${ }^{23}$ For Husserl any sort of imaginary experience, picture consciousness as well as simple imaging, gives rise to a peculiar splitting (Spaltung) of the ego in a real and a phantasy ego. ${ }^{24}$ His most famous example in this regard is the phantasy experience of a centaurs' battle (Husserl, 1965: 116; Husserl, 2005: 556). Imagining the battle, I imagine at the same time myself as assisting to it from a particular perspective given by the position of my phantasy body in the imagined world. We have here a double consciousness (cf. Husserl, 2005: 347 f., 34; see also Bernet, 2004: 6 and Marbach, 2013: 436) and to each consciousness pertains a distinct ego. On the one hand, I am conscious of my real ego imaging the centaurs'

\footnotetext{
${ }^{22}$ In the previous sections we discussed some points which address the problem of distinguishing fictional from ordinary emotions.

${ }^{23}$ For a general discussion of the phenomenon of ego-splitting in pure phantasy cf. Cavallaro (2017). In the analytical tradition, Christopher Peacocke (1985) has also argued that imagining does essentially involve imagining about oneself.

${ }^{24}$ In the case of picture consciousness, this is especially true when we look at pictures naively, thus focusing solely on the image subject. Cf. Ferencz-Flatz (2009: 246 f.). An aesthetic appreciation of pictures instead cannot just focus on the image subject, but implies a consideration of other picture components, namely the image object and the physical image - and all the dimensions associated with the understanding of the picture as an artefact. On this latter point, which is particularly important for phenomenology of art, see Lotz (2007).
} 
battle; on the other hand, I am conscious of my imaginary ego ,participating' in the imaginary world represented by the centaurs' battle. In this case, my 'participation' means simply that I am a passive spectator of the events and actions taking place during the centaurs' battle. Being an imaginary spectator always implies attending to the imagined object from a particular perspective in the fictional world and, thus, being in a certain sense within this world. Looking at a picture or freely imaging a centaurs' battle, as Husserl expresses it, "I am an actor in an imagined world" (Husserl, 1973: 313, see also 303). Thus, in experiencing fictions we are aware of ourselves at the same time in terms of a real ego and in terms of a phantasy ego (cf. Husserl, 2005: $341 \mathrm{f}$.).

The ego-splitting entails what has been called an "irrealization" or "virtualization" of the ego (de Warren, 2014: $108 \mathrm{ff}$.). This implies a process of indetermination of the real ego. As Husserl argues, the imagination produces "a pure phantasy-ego, with an undetermined corporeality, an undetermined personality, determined through the acts of grasping, attending, having of aspects, feeling of moods elicited by the artist through the picture" (Husserl, 1973: 301, all translations are mine). Husserl's account seems to anticipate Jean-Paul Sartre's phenomenology of the "irrealization" of the real-ego in the experience of imaging. In fact, also Sartre points out the necessity of irrealizing myself in order to 'act', as it were, in the fictional world of phantasy. ${ }^{25}$ However, Husserl and Sartre differ when it comes to establish the identity of the real and the phantasy ego. According to Sartre, we should distinguish "two sharply contrasted persons [...]: the imaginary me with its tendencies and desires - and the real me" (Sartre, 2004: 146). Husserl problematizes this assumption asking himself: "Is the subject in phantasy with his body identical with the real [aktuell] ego?" (Husserl, 1973: 303). We can say that to a certain extent the phantasy ego always overlaps with the real ego. This means that the character and properties of the fictional subject are not as arbitrary as those of

\footnotetext{
25 "[T] he object as imaged is an irreality. Without doubt it is present but, at the same time, it is out of reach. I cannot touch it, change its place: or rather I can indeed do so, but on the condition that I do it in an irreal way, renouncing being served by my own hands, resorting to phantom hands that will deliver irreal blows to this face: to act on these irreal objects, I must duplicate myself, irrealize myself' (Sartre, 2004: 125, see also 132).
} 
the fictional object. Surely, in certain artistic productions (e.g. literature) the phantasy ego is in part a product of the artist - notice that the phantasy ego of literature artworks, such as a novel, is not a fictional character in the story but the virtualization of the reader, who is a real subject. The author can choose what feelings the reader will have while reading the novel, shape his expectations, influence his values, and so on. Notwithstanding, the writer is not absolutely free in shaping the nature of her reader — while she certainly is in shaping that of her fictional characters. For the reader approaches the text with a stock of habits and character traits that will impinge on his appreciation of the work. To mention a controversial example, caring about the fictional character Humber Humbert from the novel Lolita is something the author Vladimir Nabokov by writing the story implicitly wants us to do. But if according to our moral tenets we resist the author's (obviously 'ironic') intention of shaping our beliefs about pedophilic love, nothing which is in the writer's power can modify it. Due to our moral convictions, we are unable to empathize with the needs and deeds of the fictional character.

In the appreciation of a literary work, the reader puts himself in the shoes of the fictional characters 'acting' in the story. This alone allows the possibility of feeling emotions related to the fictional events and characters of the story. Recently, Umberto Eco made a similar point with reference to any work of fiction. He stresses that " $[t]$ o be permanently sentimentally involved with the inhabitants of a fictional possible world we must [...] satisfy two requirements: (i) we must live in the fictional possible world as in an uninterrupted daydream; and (ii) we must in some way behave as if we were one of its characters. [...] Thus we identify ourselves with one of the fictional characters" (Eco, 2009: 93 f.). In order to react emotionally to the events depicted in a picture, written in a novel, or told by someone, a splitting between our real ego and a phantasy ego must take place. It is namely not the real but the phantasy subject the one who feels the fictional emotions, for the phantasy subject is there in the phantasy world experiencing the events of the story as quasi-real states of affairs. The spectator feels fear while watching the shower scene of Alfred Hitchcock's Psycho, because he is in a sense there 'in the scene', as it were, that is, he identifies himself with the victim under the shower and his being afraid is a 
rational reaction to the situation in which he is quasi-being in. ${ }^{26}$ Thus, the subject feeling the fictional fear is itself not the real ego of the spectator but his phantasy ego.

At this point, one could object that the splitting involved in phantasy experiences is nothing but a reduplication of the imaginative consciousness. Imaging the centaur, I would engage in two imaginative acts: the imagination of the centaur and the imagination of myself quasi-perceiving the centaur. This argument draws, first, on the principle that every kind of consciousness implies self-awareness and, second, on the view that self-awareness is a kind of objectifying consciousness. Now, it is true to identify self-awareness with an essential property of experience. As much as there is no perception without an awareness of myself perceiving this or that real object, there is also no quasiperception without an awareness of quasi-perceiving this or that fictional object. What instead is problematic in this way of arguing is the assumption that any kind of self-awareness implies an objectifying consciousness, i.e. a consciousness that explicitly poses its object as existing or, in this case, quasiexisting. The question which we should pose then is this: What is the selfawareness of a real ego imaging something? To answer it, we first ask what the proper contents of imaging consciousness are. The contents of the imagining consciousness are, first, the imagined object, say, a centaur with its fictional world, and, secondly, because of the phenomenon of phantasy ego-splitting, the phantasy ego with everything which belongs to it (phantasy body etc.). Now, the real subject is not in the same manner aware of the phantasy ego as it is of the fictional content of imaginative experience. While it is correct to identify the centaur with the intentional content of imaginative experience, the phantasy ego is in any sense the proper object of imaginative experience. I am not imagining myself when I imagine a centaur — this kind of reflective experience

${ }^{26}$ Of course, there is a difference between the fictional character Marion Crane (interpreted by Janet Leigh) who has no clue about the murder approaching her bathroom, and the spectator who can see what the movie maker allows him to see. The spectator namely knows that the murder is coming. However, he is not simply pitying the fictional character, instead he ,feels with' (mitfühlen) her. This implies for him not only being there in the scene but also being her, as it were. 
is also possible, but it is not what is happening in this case. ${ }^{27}$ One might say that the phantasy ego is a byproduct of the imagination of the centaur. It must be co-imagined with the centaur, if I have to imagine the centaur at all from a particular perspective in the phantasy space and so on. Thus, the phantasy ego is not in the same way imagined as the phantasy object. I am free (in the case of pure phantasy) to imagine the phantasy object, whereas I am not free to coimage myself in the act of quasi-perceiving the centaur.

The same applies to the experience of fictional emotions as well. We do not imagine these emotions as the intentional object of imagination acts. Surely, I can decide to imagine having such and such an emotion. But this is not the phenomenon we refer to by speaking of fictional emotions. Fictional emotions are not willingly imagined, nor do they are the intentional objects of special acts of imagination. It simply happens that we experience them by imagining certain fictional objects. We cannot help fearing with the fictional character of Psycho while watching the murder scene, which means that fictionally being afraid is not something which is at our disposal as the fact that we can decide to imagine this or that fictional object (in this case, turn on or turn off the video player). Thus, fictional emotions are, pretty much like ordinary emotions and precisely in contrast to fictional objects, not the product of willing acts but 'automatic', immediate reactions to something imaginatively represented. ${ }^{28}$

\section{Conclusion}

To conclude, the phenomenon of fictional emotions is a very rich and complex one that has been so far approached mostly by philosophers interested in a

\footnotetext{
${ }^{27}$ Husserl (2005: $221 \mathrm{f}$.) explicitly refers to the possibility of reflecting in phantasy.

${ }^{28}$ In referring to automatisms in emotional life of the phantasy subject, we want to stress once more the overlapping between phantasy ego and real ego. As we previously argued, the power of artists in eliciting emotional response to their fictions has its limits. I emotionally react to a fictional product according to those habits that are also functioning (fungierend) in my real life. The phantasy subject is thus a copy of the real ego, surely less determinate but nonetheless similar to what I really am and how I really behave in ordinary life.
} 
conceptual analysis of emotions and not by phenomenologists. ${ }^{29}$ In this paper, we hope to have paved the way towards a phenomenological understanding of the philosophical issues posed by the experience of fictional emotions. These are among others the problem of distinguishing the experience of fictional emotions from that of ordinary emotions and the problem of identifying the proper subject of fictional emotions.

\section{Bibliography}

BERNET, R. (2007). «Heimweh und Nostalgie». In: I. Därmann \& K. Busch (eds.). Pathos. Konturen eines kulturwissenschaftlichen Grundbegriffs. Bielefeld: transcript, 103-18.

- (2004). Conscience et Existence. Paris: Presses Universitaires de France.

Brough, J. B. (2005). «Translator's Introduction». In: E. Husserl. Phantasy, Image Consciousness, and Memory (1898-1925). Translated by J. B. Brough. Edmund Husserl Collected Works XI. Dordrecht: Kluwer, xxixlxviii.

CASEY, E. S. (1971). «Imagination: Imagining and the Image». Philosophy and Phenomenological Research, 31 (4): 475-490.

Cavallaro, M. (2017). "The Phenomenon of Ego-Splitting in Husserl's Phenomenology of Pure Phantasy». Journal of the British Society for Phenomenology, 48 (2): 162-77.

DE WARren, N. (2014). "Towards a Phenomenological Analysis of Virtual Fictions». Metodo. International Studies in Phenomenology and Philosophy, 2 (2): 91-112.

ECO, U. (2009). "On the Ontology of Fictional Characters: A Semiotic Approach». Sign Systems Studies, 37 (1/2): 82-98.

FERENCZ-Flatz, C. (2009). «Gibt es perzeptive Phantasie? Als-ObBewusstsein, Widerstreit und Neutralität in Husserls Aufzeichnungen zur Bildbetrachtung». Husserl Studies, 25 (3): 235-253.

HuSSERL, E. (2005). Phantasy, Image Consciousness, and Memory (18981925). Translated by J. B. Brough. Edmund Husserl Collected Works XI. Dordrecht: Kluwer.

- (2001 [1900/1901]). Logical Investigations. Volume 2. Edited by D. Moran.

${ }^{29}$ Though, consider the listing of some important exceptions in this sense above in footnote 20 . 
Translated by J. N. Findlay. London -New York: Routledge.

- (1973). Zur Phänomenologie der Intersubjektivität. Texte aus dem Nachlaß . Erster Teil: 1905 - 1920. Edited by I. Kern. Husserliana XIII. Dordrecht: Kluwer.

- (1965). Erste Philosophie (1923/24): Zweiter Teil: Theorie der Phänomenologischen Reduktion. Edited by R. Boehm. Husserliana VIII. Dordrecht: Martinus Nijhoff.

JANSEN, J. (2005a). «On the Development of Husserl's Transcendental Phenomenology of Imagination and Its Use for Interdisciplinary Research». Phenomenology and the Cognitive Sciences, 4 (2): 121-132.

- (2005b). «Phantasy's Systematic Place in Husserl's Work». In: R. Bernet, D. Welton, \& G. Zavota (eds.). Edmund Husserl: Critical Assessments of Leading Philosophers. Routledge: New York, 221-243.

KÜNNE, W. (2007). «Fiktion ohne fiktive Gegenstände: Prolegomena zu einer Fregeanischen Theorie der Fiktion». In: M. E. Reicher (ed.). Fiktion, Wahrheit, Wirklichkeit: Philosophische Grundlagen der Literaturtheorie. Paderborn: mentis, 54-71.

LEVINSON, J. (2006). «Emotion in Response to Art». In: J. Levinson, Contemplating Art: Essays in Aesthetics. Oxford: Oxford University Press, $38-55$.

LotZ, C. (2007). «Depiction and Plastic Perception. A Critique of Husserl's Theory of Picture Consciousness». Continental Philosophy Review, 40 (2): 171-85.

MARBACH, E. (2013). «Towards a Phenomenological Analysis of Fictional Intentionality and Reference». International Journal of Philosophical Studies, 21 (3): 428-47.

Melle, U. (1990). «Objektivierende und nicht-objektivierende Akte». In: S. Ijsseling (ed.). Husserl-Ausgabe und Husserl-Forschung. Phaenomenologica 115. Boston-London: Kluwer, 35-49.

MORAN, R. (1994). «The Expression of Feeling in Imagination». The Philosophical Review, 103 (1): 75-106.

NI, L. (2007). «The Problem of the Phenomenology of Feeling in Husserl and Scheler». In: K.-Y. Lau \& J. J. Drummond (eds.). Husserl's Logical Investigations in the New Century: Western and Chinese Perspectives. Phaenomenologica 55. Dordrecht: Springer, 67-82.

PEACOCKE, C. (1985). «Imagination, Experience, and Possibility. A Berkleyan View Defended». In: J. Foster \& H. Robinson (eds.). Essays on Berkeley: A Tercentennial Celebration. Oxford: Clarendon, 19-35.

RADFORD, C. (1975). «How Can We Be Moved by the Fate of Anna Karenina?». Proceedings of the Aristotelian Society, Supplementary 
Volumes 4, 67-80.

RozZONI, Claudio (2017). «From Abbild to Bild?: Depiction and

Resemblance in Husserl's Phenomenology». Aisthesis. Pratiche,

linguaggi e saperi dell'estetico, 10 (1): 117-130.

SARTRE, J.-P. (2004 [1940]). The Imaginary: A Phenomenological Psychology

of the Imagination. London-New York: Routledge.

SOKOLOWSKI, R. (1970). The Formation of Husserl's Concept of Constitution.

Phaenomenologica 18. The Hague: Martinus Nijhoff.

SuMMA, M. (2019). «Are Fictional Emotion Genuine and Rational?

Phenomenological Reflections on a Controversial Question». New

Yearbook for Phenomenology and Phenomenological Philosophy, 17: .

VENDRELl FERRAN, Í. (2014). «Das Paradoxon Der Fiktion». In: T. Klauk \&

T. Köppe (eds.). Fiktionalität. Ein intersdisziplinäres Handbuch. BerlinBoston: De Gruyter, 313-337.

- (2010). «Ästhetische Erfahrung und Quasi-Gefühle». In: V. Raspa (ed.). The Aesthetics of the Graz School. Meinong Studies 4. Berlin-Boston: De Gruyter, 129-168.

Walton, K. L. (1990). Mimesis as Make-Believe. On the Foundations of the Representational Arts. Cambridge, MA: Harvard University Press.

MARCO CAVALlARO is completing his $\mathrm{PhD}$ at the University of Cologne on Husserl's extension of the concept of Wissenschaftslehre during the Göttingen years. He is currently research associate at the Husserl Archive Cologne and the a.r.t.e.s. Graduate School for the Humanities Cologne. His major research focus is on Husserl's phenomenology, philosophy of science, and practical philosophy. He published so far for scientific journals such as Phänomenologische Forschungen, Investigationes Fenomenológicas, Journal of the British Society for Phenomenology, and Husserl Studies. He is working on the first English monograph on Husserl's concept of habit and editing three collective volumes on Husserl and phenomenology. 